Article

\title{
Comparison of an Offline SPE-GC-MS and Online HS-SPME-GC-MS Method for the Analysis of Volatile Terpenoids in Wine
}

\author{
Cody Williams $\mathbb{D}$ and Astrid Buica *(D) \\ Department of Viticulture and Oenology, Stellenbosch University, Stellenbosch 7600, South Africa; \\ codyw@sun.ac.za \\ * Correspondence: abuica@sun.ac.za
}

Received: 13 November 2019; Accepted: 31 January 2020; Published: 4 February 2020

\begin{abstract}
The aroma profile is an important marker for wine quality. Various classes of compounds are responsible for the aroma of wine, and one such class is terpenoids. In the context of this work, a validated gas chromatography-mass spectrometry (GC-MS) method for the quantitation of terpenoids in red and white wine using headspace solid-phase microextraction (HS-SPME) and solid-phase extraction (SPE) was established. Calibrations were performed in the respective base wine using both sample preparation methods. The linearity, precision and accuracy evaluated for the respective matrices were excellent for both sample preparations. However, the HS-SPME approach was more sensitive and more accurate. For both sample preparations, the quantification limits were lower than the odor thresholds in wine. The terpenoid concentrations $(\mu \mathrm{g} / \mathrm{L})$ were evaluated for 13 white wines using both sample preparation methods. Importantly, the online HS-SPME approach was more sensitive than the offline SPE method. The major terpenoids identified in the white wines evaluated were linalool $(0.2-63 \mu \mathrm{g} / \mathrm{L})$, geraniol (nd-66 $\mu \mathrm{g} / \mathrm{L}$ ) and $\alpha$-terpineol (nd-85 $\mu \mathrm{g} / \mathrm{L}$ ).
\end{abstract}

Keywords: wine; terpenoid; terpene; solid-phase extraction; solid-phase microextraction; gas chromatography; mass spectrometry

\section{Introduction}

Aroma is an important parameter when evaluating the quality of grapes and wine [1]. The aroma profile is attributed to a variety of compounds which can be separated into various classes based on their chemical structure [2]. Selected classes include esters ('fruity'/'floral') [3], fatty acids ('rancid') [4,5], $\mathrm{C}_{6}$ alcohols and aldehydes ('leafy', 'green') [6], methoxypyrazines ('green capsicum') [7], varietal thiols ('grapefruit', 'guava', 'granadilla') [8], volatile phenols ('smoke') [9], reductive sulfur compounds ('cabbage') [10], lactones ('wood') [11], carbonyl compounds ('creamy') [12], and terpenoids ('floral') [2,13]. In the context of this work, terpenoids and $\mathrm{C}_{13}$ norisoprenoids are of particular importance, as they contribute to some highly desirable descriptors such as 'floral', 'raspberry', 'tobacco', 'honey', and 'citrus' notes [14].

Terpenes are by definition isoprenoids, which consist of the basic $\mathrm{C}_{5} \mathrm{H}_{8}$ unit, bound in a head-to-tail manner. The most prominent forms in the aroma profile of wine are the $\mathrm{C}_{10}$-monoterpenes, $\mathrm{C}_{15}$-sesquiterpenes and $\mathrm{C}_{13}$-norisoprenoids $[15,16]$. Terpenoids are secondary plant constituents which are mainly formed via a biosynthenthetic pathway; on the other hand, $\mathrm{C}_{13}$-norisoprenoids are usually derived from the oxidative degradation of diterpenes and carotenoids $[17,18]$. Although the presence of these aroma compounds is highly sought after in wines, the complexity of the wine matrix accompanied by the inherent low concentrations in wine already indicates the difficulty in the analysis of these compounds. The isolation of terpenoids often includes a pre-concentration step and/or the use of 
highly sensitive instrumentation [19]. Due to the possibility of terpene oxidation and rearrangements, the analysis technique should be rapid, simple and robust [2,20-22]. Terpenoid identification in wines and grapes has been discussed in reviews [23-25] and the various sample preparation strategies such as liquid-liquid extraction (LLE), liquid-liquid microextraction (LLME), solid-phase extraction (SPE), headspace-solid-phase microextraction (HS-SPME), stirrer bar sorptive extraction (SBSE) and purge-and-trap methods are well documented [1,14,19,22,26-31].

Although LLE and SPE are highly versatile and easily accessible techniques, common drawbacks include the generation of organic solvent waste, the use of large volumes of wine often required for sufficient concentration, and the fact that the sample preparation methods are generally offline, which in turn results in longer sample preparation time. In contrast, online HS-SPME is a technique developed in the 90s, which makes use of a fused-silica fiber often coated with a suitable stationary phase [32]. In comparison to the above-mentioned techniques, HS-SPME is generally faster and more efficient, more sensitive and is solvent-free [32].

As mentioned before, the aroma profile of a wine consists of a myriad of volatile compounds and the common technique for their analysis is gas chromatography with either flame-ionization (GC-FID) or mass spectrometry detection (GC-MS). Due to the complexity of wine, mass spectrometry is commonly used as an additional source of analyte confirmation to the more general retention time. As methods for the quantitation of terpenoids have been reported using both SPE and HS-SPME, there is a lack of literature on the comparison of the performance of these sample preparations using SPE vs. HS-SPME. Herein, we report the development and method performance parameters of an offline SPE-GC-MS and online HS-SPME-GC-MS method for the analysis of free terpenoids in red, white and model wines and application of both sample preparation methods in the analysis of free terpenoids in white wine (Scheme 1).

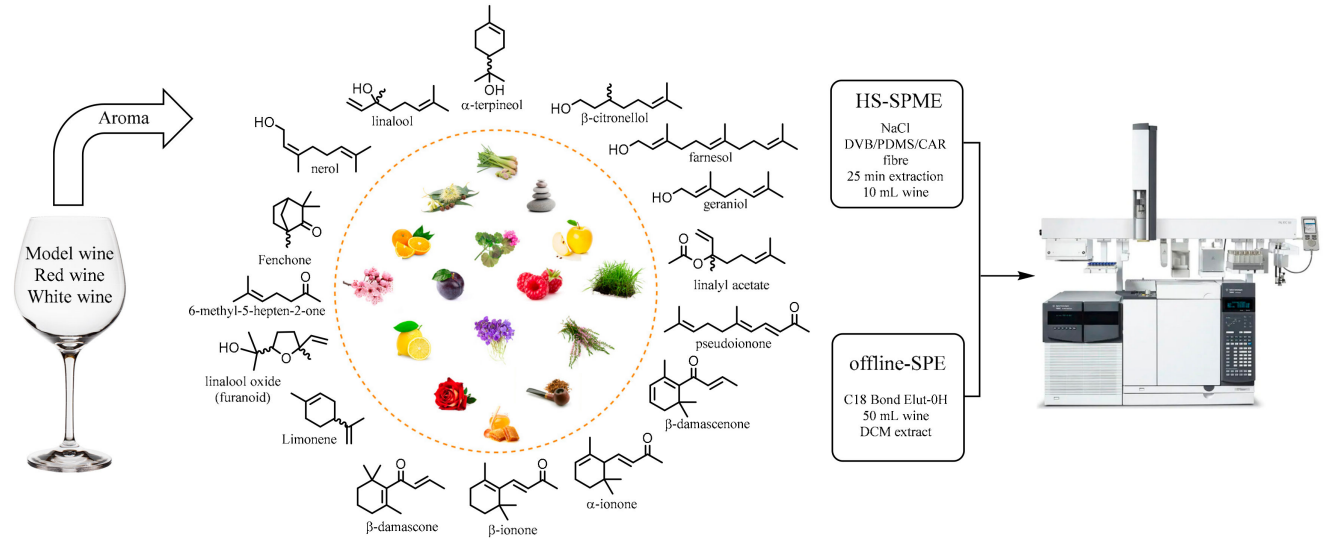

Scheme 1. Schematic for the online headspace - solid-phase microextraction (HS-SPME) and offline solid phase extraction - gas chromatography - mass spectrometry (SPE-GC-MS) analyses of free terpenoids in wine.

\section{Results and Discussion}

\subsection{Sample Preparation}

The sample preparation used in this method for wine was rapid, simple, and resulted in improved sensitivity when compared to literature. Different methods proposed in literature use large sample volumes (up to $100 \mathrm{~mL}$ ) [2,33], large volumes of organic solvent (up to $40 \mathrm{~mL}$ ) [33,34], long extraction times (up to $60 \mathrm{~min}$ ) [17] and long analysis times (up to $118 \mathrm{~min}$ ) [17,33,35-38]. In comparison to the sample preparation methods in the current study, the volume of wines for the offline SPE sample preparation is $50 \mathrm{~mL}$ and the volume of organic solvent used is $10 \mathrm{~mL}$. The online HS-SPME method uses $10 \mathrm{~mL}$ of wine and the samples are extracted for $25 \mathrm{~min}$. The instrument run time for both sample preparation methods is $49 \mathrm{~min}$ (Table 1 ). 
Table 1. Selected sensory parameters for terpenoids.

\begin{tabular}{cccc}
\hline Compound & $\begin{array}{c}\text { CAS } \\
\text { Number }\end{array}$ & $\begin{array}{c}\text { OTDs } \\
(\mu \mathrm{g} / \mathrm{L})\end{array}$ & $\begin{array}{c}\text { Odor } \\
\text { Descriptor }\end{array}$ \\
\hline $\begin{array}{c}\text { Limonene } \\
\text { 6-Methyl-5-hepten-2-one }\end{array}$ & $5989-27-5$ & $15[39]$ & citrus [13] \\
Fenchone & $110-93-0$ & $50[40]$ & $\begin{array}{c}\text { citrus-like [41] } \\
\text { muddy [43], earthy [42] }\end{array}$ \\
cis-Linalool oxide (furanoid) & $7787-20-4$ & $110[42]$ & - \\
trans-Linalool oxide (furanoid) & $1365-19-1$ & $320[45]$ & $\begin{array}{c}\text { elderflower, leaves, sweet [44] } \\
\text { woody [45] }\end{array}$ \\
Linalool & $7895-77-2$ & $25[46]$ & Floral [47], lavender [13] \\
Linalyl acetate & $115-95-7$ & $110[48]$ & floral, sweet, mint, \\
caraway-like [48] \\
$\alpha$-terpineol & $98-55-5$ & $250[46]$ & oily, anise, spicy [13] \\
$\beta$-Citronellol & $106-22-9$ & $18[39]$ & citrus, floral [47] \\
Nerol & $106-25-2$ & $15[39]$ & orange, floral, lemongrass [49] \\
$\beta$ fruity, floral, plum, rose [18] \\
$\beta$-Damascone & $23726-91-2$ & - & tobacco, apple, floral, rose [49] \\
Geraniol & $23696-85-7$ & $0.05[50]$ & floral [47], geranium [49] \\
$\alpha$-Ionone & $106-24-1$ & $30[50]$ & floral [49] \\
$\beta$-Ionone & $127-41-3$ & $2.6[46]$ & raspberry, floral [49] \\
cis-PseudoIonone & $14901-07-6$ & $0.09[46]$ & - \\
trans-PseudoIonone & $13927-47-4$ & $800[40]$ & - \\
Farnesol $(Z, E)$ & $3548-78-5$ & $800[40]$ & - \\
Farnesol $(E, Z)$ & $3790-71-4$ & - & - \\
Farnesol $(E, E)$ & $3879-60-5$ & - & floral, oily, blueberry [51-53] \\
\hline
\end{tabular}

Odor thresholds are reported for a wine matrix except for 6-methyl-5-hepten-2-one (water), pseudoionone (water) and linalyl acetate (air).

\subsection{Comparison of the Figures of Merit for Method Testing Parameters}

The sample preparation methods were compared with respect to the qualitative (selectivity) and quantitative (linearity, precision, and accuracy) parameters.

The selectivity of the sample preparation methods was evaluated by comparing the terpenoids peaks in the chromatogram, in the presence and absence of interferences from the matrix. Retention indices were calculated for each compound and used for comparison purposes. The offline SPE (Figure S1a) and online HS-SPME (Figure S1b) total ion chromatograms in spiked model, spiked dearomatized white and a real white wine are provided in the Supplementary Materials (Figure S1). When comparing the sample preparations, notably more chemical interferences were observed using the HS-SPME approach. The rationale for this is that the DVB/PDMS/CAR fiber is commonly used for untargeted analyses due to its good extraction capability of a wide range of analytes (lower selectivity), which extrapolates to the observation of more chemical noise in the chromatography [54]. Regardless of the interferences observed, the compounds could still be quantified. A total of 20 compounds was quantified when using the method in the current study.

Both sample preparation methods showed excellent linear response in all of the matrices tested, as measured by the correlation coefficients $\left(\mathrm{R}^{2}\right)$. In the context of calibration curves, the slope in all of the matrices were similar, which implies that a calibration may be performed in model wine and subsequently unknowns may be quantified with minor over- or underestimations in wines. For a practical determination of terpenoids, the analytical method should be able to measure concentrations below the odor threshold, which would allow for combined sensory and chemistry experiments. Notably, the LOQ for all terpenoids was below the ODTs in wine (Table 1). In addition, the LODs for both sample preparation methods were lower than those reported in literature. The limit of detection (LOD) and limit of quantitation (LOQ) for both sample preparations in the respective matrices are reported in Table 2. Notably, the LOD for the online HS-SPME method was much lower in comparison to the offline SPE method (as reported back to the original $50 \mathrm{~mL}$ sample) for most compounds, excluding 6-methyl-5-hepten-2-ol and geraniol, in model and white wine. Conversely, the LOD in red wines was higher for HS-SPME in comparison to SPE; this could be explained by the presence of more noise observed in the red wine samples, resulting in lower signal to noise ratios (SNRs) and consequently higher calculated LOD's. 
Table 2. Selected method performance parameters for the quantitation of terpenoids in model (MW), red (RW) and white wine (WW) using both offline SPE and online HS-SPME GC-MS analysis.

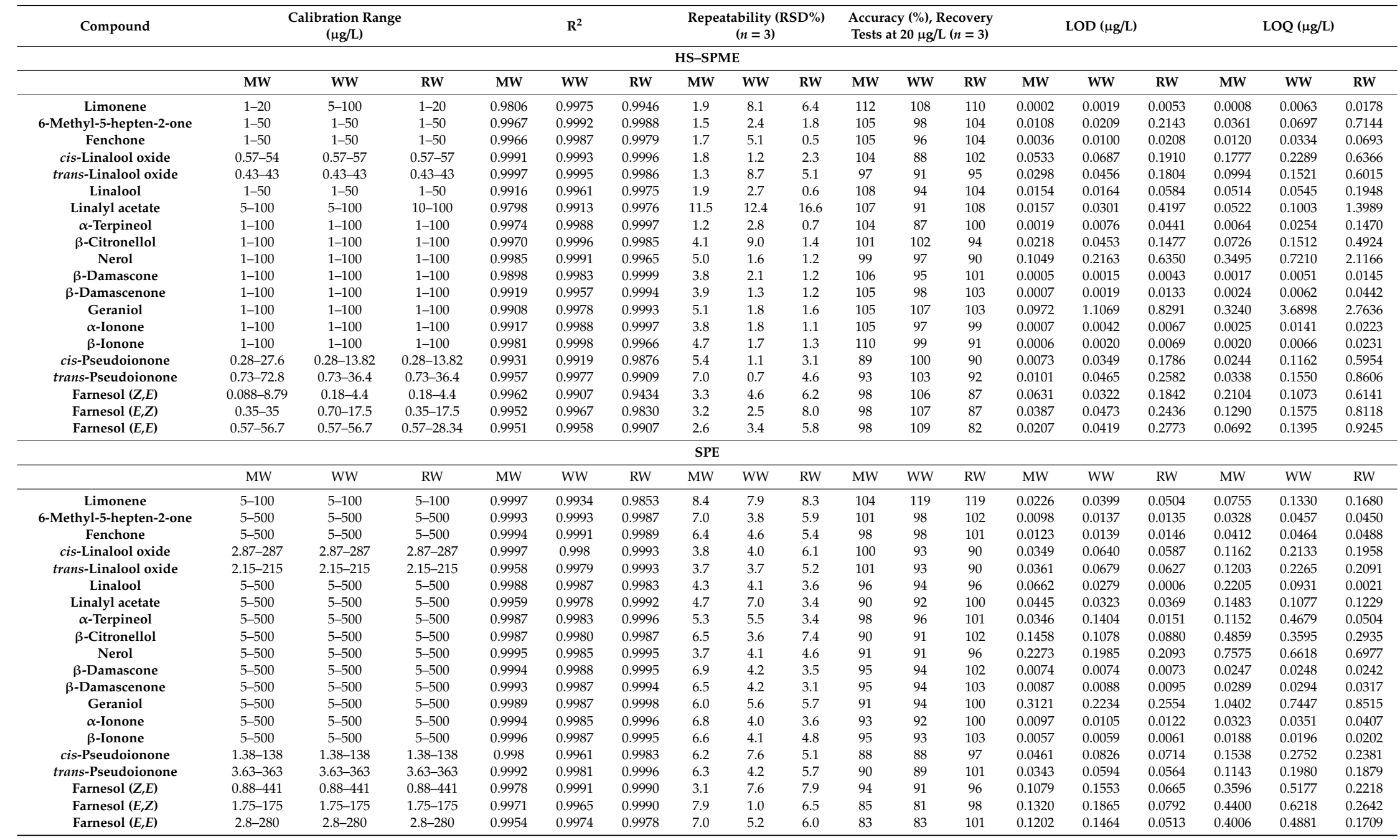


The precision for the entire method (sample preparation and instrumental method) was evaluated by repeating the extraction of terpenoids at two calibration levels. The repeatability (expressed as RSD) was calculated based on concentrations and retention times of the analytes (Table 2). For both sample preparation methods, the retention time RSD was less than $0.6 \%$. The calculated concentration repeatability was generally better for the online HS-SPME method in comparison to the off-line SPE method which is explained by the inherent operator influence for the entire offline SPE procedure. With respect to the matrices tested, the RSD was on average higher in model wine in comparison to white and red wine for both SPE and HS-SPME. The combined sample preparation and instrumental precision were acceptable for the determination of terpenoids in wine (RSD $<9 \%$ for SPE and $<17 \%$ for HS-SPME).

Accuracy of the HS-SPME and offline SPE sample preparation methods was determined via recovery tests, which allow for the quantitation of the analytes in the absence and presence of interferences. The recovery values in all matrices for both methods ranged between 81 and $119 \%$ using 3-octanol as the internal standard. The recovery in both white and red wines were acceptable for the SPE method as compared to Piñeiro et al. [19] and Dziadas and Jelen [2]. For the HS-SPME method, the recovery of selected terpenoids in Madeira wine reported by Marques and co-workers $[17,28]$ ranged from 54 to $115 \%$. The current study indicates that the recovery in white wine was generally better for nerol, $\beta$-damascenone, geraniol, $\alpha$-ionone and $\beta$-ionone when compared to work by Marques and co-workers $[17,28]$.

Practicaly, HS-SPME requires a headspace autosampler, which is expensive tool and it is not present in all analytical laboratories. Hence, based on the method performance parameters examined, the offline SPE method was considered as a practical alternative tool in the analysis of terpenes in wine which resulted in acceptable method performance parameters.

\subsection{Internal Standard Comparison}

It is considered ideal to use deuterated compounds as internal standards to model the behavior of the analytes of interest throughout the analytical method when MS is used as a detector. Due to the high cost and rare nature of deuterated terpenoid standards, the work aimed to examine the differences between 3-octanol and 2,6-dimethyl-6-hepten-2-ol as practical and commercially available internal standards. Initially 2-octanol was used due to its precedence in literature [14,19,37,43,54]; however, co-elution was observed with fenchone, which prompted the use 3-octanol as an internal standard instead [28,55]. 2,6-Dimethyl-6-hepten-2-ol was also selected based on its chemical structure, as it contains an isoprene unit, which is inherent to terpenoid compounds. The method performance data showed that 3-octanol was well adapted to both the SPE and HS-SPME approaches for the analysis of terpenoids in wine, which suggested that the use of deuterated analyte analogues was not essential in this case. The combined sample preparation and instrument repeatability values were better using 2,6-dimethyl-6-hepten-2-ol (Table S1, see Supplementary Materials). This observation was expected as 2,6-dimethyl-6-hepten-2-ol is structurally more similar to the terpenoids than 3-octanol, and hence the former would account for any analyte losses during the sample preparation and instrument analyses. A similar trend was observed when comparing the recoveries for the different internal standards, 2,6-dimethyl-6-hepten-2-ol internal standard modelled the extraction process better than 3-octanol. This was observed for most compounds except for the linalool oxides and linalyl acetate when compared using both sample preparation methods. Although 2,6-dimethyl-6-hepten-2-ol internal standard outperformed 3-octanol, the former is no longer commercially available. Furthermore, the method performance using 3-octanol was still acceptable. Therefore, due to its availability, precedence in literature, and means to compare it to future work, 3-octanol was chosen as the internal standard for the further analyses of terpenoids in wine samples. 


\subsection{Volatile Terpenoid Quantification in White Wine}

The procedures developed were successfully applied in the determination of volatile terpenoids in white wine and consequently compared. The concentrations determined by SPE and HS-SPME are shown in Table 3. Using the SPE method, the major terpenoids present were linalool (range 0.6-64 $\mu \mathrm{g} / \mathrm{L}$ ), $\alpha$-terpineol (range nd-86 $\mu \mathrm{g} / \mathrm{L}$ ), geraniol (range nd-66 $\mu \mathrm{g} / \mathrm{L}$ ) and cis-linalool oxide (range 0.07-31 $\mu \mathrm{g} / \mathrm{L}$ ). The total terpenoid concentrations for the SPE sample preparation method ranged from 13 to $232 \mu \mathrm{g} / \mathrm{L}$. Using the HS-SPME sample preparation method, the total terpenoid concentrations ranged from 15 to $192 \mu \mathrm{g} / \mathrm{L}$. The concentration ranges are comparable to terpenoid concentration found in non-aromatic white wines $[2,13,17,19,56]$. The major constituents in the wines when using the HS-SPME method were linalool (range 0.09-38 $\mu \mathrm{g} / \mathrm{L}$ ), $\alpha$-terpineol (range 0.9-56 $\mu \mathrm{g} / \mathrm{L}$ ), geraniol (range 3.2-79 $\mu \mathrm{g} / \mathrm{L}$ ) and cis-linalool oxide (range 2.3-21 $\mu \mathrm{g} / \mathrm{L}$ ). In comparison to the SPE method, B-ionone was quantified in 11 more wines and trans-pseudoionone was also quantified in 12 more wines when using the HS-SPME method. These observations are in line with the method performance data, which reiterates that the HS-SPME method is more sensitive than the SPE method. There are various reports on the quantitation of pseudoionone as a sum of the steroisomers in different matrices [18,40]. To the best of our knowledge, herein is the first report of the quantitation of individual cis/trans pseudoionone isomers in wine. The trans-pseudoionone concentrations ranged from nd to $1.1 \mu \mathrm{g} / \mathrm{L}$ and cis-pseudoionone concentrations ranged from nd to $1.48 \mu \mathrm{g} / \mathrm{L}$. 
Table 3. Description and terpenoid quantitation (expressed in $\mu \mathrm{g} / \mathrm{L}$ ) in white wine ${ }^{1}$ using the online HS-SPME sample preparation method and offline SPE sample preparation method, respectively.

\begin{tabular}{|c|c|c|c|c|c|c|c|c|c|c|c|c|c|c|}
\hline Online HS-SPME & FLY16S & ARV16S & ANI16/17S & JCB16CH & FRN17SB & FLK17AL & KZC18CB & KLA16S & ORB17AL & LNC17SB & ARV16S/B & GWZ19C & GWC19E & MRF17SB \\
\hline Limonene & $<\mathrm{LOQ}$ & $<\mathrm{LOQ}$ & $<\mathrm{LOQ}$ & $<\mathrm{LOQ}$ & $<\mathrm{LOQ}$ & 0.27 & $<\mathrm{LOQ}$ & $<$ LOQ & $<\mathrm{LOQ}$ & $<$ LOQ & 24.39 & 0.13 & 0.01 & $<\mathrm{LOQ}$ \\
\hline 6-Methyl-5-hepten-2-one & $<$ LOQ & $<\mathrm{LOQ}$ & 0.06 & $<$ LOQ & $<$ LOQ & 0.8 & 0.46 & $<$ LOQ & $<\mathrm{LOQ}$ & $<$ LOQ & 0.31 & 0.87 & 1.06 & $<$ LOQ \\
\hline Fenchone & $<$ LOQ & $<\mathrm{LOD}$ & $<$ LOD & $<\mathrm{LOQ}$ & $<$ LOQ & $<$ LOQ & $<$ LOQ & $<$ LOQ & $<$ LOQ & $<$ LOQ & $<$ LOQ & $<\mathrm{LOQ}$ & $<$ LOQ & $<\mathrm{LOQ}$ \\
\hline$c i s$-Linalool oxide & 20.79 & 8.1 & 18.93 & 6.58 & 4.84 & 20.56 & $<\mathrm{LOD}$ & 19.08 & 2.84 & 10.33 & 14.01 & 5.53 & 2.34 & 3.69 \\
\hline trans-Linalool oxide & 6.14 & 3.07 & 5.96 & 2.84 & 1.77 & 21.38 & 0.78 & 5.38 & 4.71 & 3.86 & 4.81 & 3.24 & 2.22 & 1.7 \\
\hline Linalool & 0.29 & 0.82 & 1.31 & 1.93 & 2.06 & 37.9 & 2.44 & 2.13 & 15.22 & 3.49 & 0.1 & 22.04 & 14.6 & 3.96 \\
\hline Linalyl acetate & $<\mathrm{LOQ}$ & $<\mathrm{LOQ}$ & $<$ LOQ & $<\mathrm{LOD}$ & $<\mathrm{LOD}$ & $<\mathrm{LOD}$ & $<\mathrm{LOD}$ & $<\mathrm{LOQ}$ & $<\mathrm{LOD}$ & $<\mathrm{LOQ}$ & $<$ LOQ & $<$ LOQ & $<\mathrm{LOQ}$ & $<\mathrm{LOD}$ \\
\hline$\alpha$-Terpineol & $2.92^{2}$ & 4.03 & 4.11 & 4.97 & 3.18 & 56.23 & 0.91 & $4.73^{\circ}$ & 11.79 & 12.68 & 5.21 & 10.76 & 6.3 & 3.46 \\
\hline$\beta$-Citronellol & 1.35 & 0.76 & 1.73 & 1.81 & 1.75 & 5.27 & 2.13 & 1.61 & 3.13 & 2.24 & 0.52 & 34 & 75.43 & 3.69 \\
\hline Nerol & 0.76 & 2.08 & $<\mathrm{LOD}$ & 5.05 & 5.55 & 7.82 & 0.76 & 3.46 & 2.92 & 7.19 & 2.1 & 13.78 & 21.04 & $<$ LOD \\
\hline$\beta$-Damascone & 0.01 & $<\mathrm{LOQ}$ & $<\mathrm{LOQ}$ & $<\mathrm{LOQ}$ & $<\mathrm{LOQ}$ & $<\mathrm{LOQ}$ & $<\mathrm{LOQ}$ & $<\mathrm{LOQ}$ & $<\mathrm{LOQ}$ & $<$ LOQ & $<$ LOQ & $<\mathrm{LOQ}$ & $<$ LOQ & $<\mathrm{LOQ}$ \\
\hline$\beta$-Damascenone & 0.64 & 0.75 & $0.66^{\circ}$ & 0.74 & 0.27 & 1.31 & 0.35 & $1.69^{\circ}$ & $1.68^{-}$ & $<$LOQ & 2.45 & 3.24 & 1.75 & 1.45 \\
\hline Geraniol & 3.27 & 64.39 & 9.45 & 5.41 & 6.49 & 20.21 & 3.48 & 3.56 & 8.67 & 7.77 & 78.95 & 60.22 & 63.37 & 13.14 \\
\hline$\alpha$-Ionone & 0.04 & $<\mathrm{LOQ}$ & $<\mathrm{LOQ}$ & $<\mathrm{LOQ}$ & $<\mathrm{LOQ}$ & $<\mathrm{LOQ}$ & $<\mathrm{LOQ}$ & $<\mathrm{LOQ}$ & $<\mathrm{LOQ}$ & $<\mathrm{LOQ}$ & $<$ LOQ & $<\mathrm{LOQ}$ & $<\mathrm{LOQ}$ & $<\mathrm{LOQ}$ \\
\hline$\beta$-Ionone & 0.26 & 0.06 & 0.04 & 0.13 & 0.03 & 0.03 & 0.03 & 0.04 & 0.03 & 0.01 & 0.32 & 0.02 & 0.02 & 0.03 \\
\hline cis-Pseudoionone & $<\mathrm{LOD}$ & $<$ LOD & $<$ LOD & $<$ LOD & $<\mathrm{LOD}$ & $<$ LOD & $<$ LOD & $<$ LOD & $<$ LOD & $<$ LOD & 0.36 & $<$ LOD & $<$ LOD & $<\mathrm{LOD}$ \\
\hline trans-Pseudoionone & 0.27 & 0.34 & 1.02 & 0.35 & 0.23 & 0.18 & 0.32 & 0.2 & 0.16 & 0.19 & 1.11 & 0.29 & 0.29 & 0.28 \\
\hline Farnesol $(Z, E)$ & 0.11 & $<\mathrm{LOD}$ & 0.05 & 0.63 & 0.1 & 0.29 & 0.21 & 0.06 & 0.42 & 0.03 & 0.03 & 0.01 & 0.01 & 0.62 \\
\hline Farnesol $(E, Z)$ & $<\mathrm{LOD}$ & $<$ LOD & $<$ LOD & $<$ LOD & $<$ LOD & $<$ LOD & $<$ LOD & $<$ LOD & $<$ LOD & $<$ LOD & 0.32 & $<$ LOD & $<$ LOD & $<$ LOD \\
\hline Farnesol $(E, E)$ & 0.15 & 0.11 & 0.4 & 1.77 & 0.53 & 0.69 & 3.66 & 0.09 & 1.87 & 0.06 & 0.91 & 3.12 & 3.24 & 1.87 \\
\hline Offline SPE & FLY16S & ARV16S & ANI16/17S & JCB16CH & FRN17SB & FLK17AL & KZC18CB & KLA16S & ORB17AL & LNC17SB & ARV16S/B & GWZ19C & GWC19E & MRF17SB \\
\hline Limonene & $<\mathrm{LOQ}$ & $<\mathrm{LOQ}$ & $<\mathrm{LOQ}$ & $<\mathrm{LOQ}$ & $<\mathrm{LOQ}$ & $<\mathrm{LOQ}$ & $<$ LOQ & $<\mathrm{LOQ}$ & $<\mathrm{LOQ}$ & $<$ LOQ & $<$ LOQ & $<\mathrm{LOQ}$ & $<\mathrm{LOQ}$ & $<\mathrm{LOQ}$ \\
\hline 6-Methyl-5-hepten-2-one & $<$ LOD & $<$ LOD & $<$ LOQ & 0.02 & $<$ LOD & 0.91 & 0.53 & $<$ LOD & $<\mathrm{LOD}$ & $<\mathrm{LOD}$ & 0.07 & 1.68 & 1.63 & $<$ LOD \\
\hline Fenchone & $<\mathrm{LOD}$ & $<$ LOD & $<$ LOD & $<$ LOD & $<$ LOD & $<$ LOD & $<$ LOD & $<$ LOD & $<$ LOD & $<$ LOD & $<$ LOD & $<$ LOD & $<$ LOD & $<\mathrm{LOD}$ \\
\hline$c i s$-Linalool oxide & 24.5 & 11.01 & 19.81 & 11.12 & 8.11 & 30.41 & 0.07 & 16.48 & 4.24 & 18.26 & 12.89 & 1.39 & 0.87 & 5.17 \\
\hline trans-Linalool oxide & 8.23 & 3.48 & 5.84 & 4.1 & 2.7 & 21.62 & 0.19 & 5.15 & 1.32 & 4.65 & 4.33 & 1.45 & 1.18 & 1.19 \\
\hline Linalool & 1.45 & 1.66 & 2.37 & 4.22 & 3.41 & 63.16 & 4.04 & 8.02 & 21.51 & 5.33 & 0.62 & 19.09 & 12.43 & 6.01 \\
\hline Linalyl acetate & $<\mathrm{LOD}$ & $<\mathrm{LOD}$ & $<\mathrm{LOD}$ & $<\mathrm{LOD}$ & $<\mathrm{LOD}$ & $<\mathrm{LOD}$ & $<\mathrm{LOD}$ & $<$ LOD & $<\mathrm{LOD}$ & $<\mathrm{LOD}$ & $<\mathrm{LOD}$ & $<\mathrm{LOD}$ & $<\mathrm{LOD}$ & $<\mathrm{LOD}$ \\
\hline$\alpha$-Terpineol & 3.46 & 4.7 & 4.87 & 5.97 & 2.99 & 85.92 & $<$ LOQ & 7.01 & 14.83 & 18.97 & 6.02 & 3.81 & 1.72 & 3.4 \\
\hline$\beta$-Citronellol & 2.12 & 1.47 & 2.36 & 2.35 & 2.32 & 5.98 & 2.64 & 2.81 & 3.29 & 2.68 & 1.23 & 48.86 & 92.34 & 3.7 \\
\hline Nerol & $<$ LOD & $<$ LOD & $<$ LOD & $<\mathrm{LOD}$ & $<$ LOD & 5.92 & $<$ LOD & $<$ LOD & 2.88 & $<$ LOD & $<$ LOD & 18 & 24.25 & $<\mathrm{LOD}$ \\
\hline$\beta$-Damascone & $<\mathrm{LOQ}$ & $<\mathrm{LOQ}$ & $<\mathrm{LOQ}$ & $<\mathrm{LOQ}$ & $<\mathrm{LOQ}$ & $<$ LOQ & $<\mathrm{LOQ}$ & $<\mathrm{LOQ}$ & $<\mathrm{LOQ}$ & $<\mathrm{LOQ}$ & $<\mathrm{LOQ}$ & $<\mathrm{LOQ}$ & $<\mathrm{LOQ}$ & $<\mathrm{LOQ}$ \\
\hline$\beta$-Damascenone & 0.98 & 1.19 & 1.19 & 1.07 & 0.71 & 1.61 & 0.86 & 2.42 & 1.68 & 0.36 & 2.97 & 3.79 & 2.01 & 1.47 \\
\hline Geraniol & $<\mathrm{LOD}$ & 9.63 & 0.4 & 1.5 & 1.7 & 14.7 & 2.8 & $<$ LOD & 6.01 & 3.5 & 13.68 & 66.92 & 60.07 & 4.78 \\
\hline$\alpha$-Ionor & $<\mathrm{LOD}$ & $<$ LOD & $<$ LOD & $<$ LOD & $<$ LOD & $<\mathrm{LOD}$ & $<$ LOD & $<\mathrm{LOD}$ & $<\mathrm{LOD}$ & $<\mathrm{LO}$ & $<$ LOD & 0.7 & 0.75 & $<\mathrm{LOD}$ \\
\hline$\beta$-Ionone & $<$ LOD & $<\mathrm{LC}$ & $<$ LOD & $<$ LOD & $<\mathrm{LOD}$ & 0.42 & $<\mathrm{LC}$ & 0.4 & $<\mathrm{LOD}$ & $<\mathrm{LOD}$ & 0.51 & $<\mathrm{LOD}$ & $<\mathrm{LOD}$ & $<\mathrm{LOD}$ \\
\hline cis-Pseudoionone & $<$ LOD & $<$ LOD & $<$ LOD & $<$ LOD & $<$ LOD & $<$ LOD & $<$ LOD & $<$ LOD & $<\mathrm{LOD}$ & $<\mathrm{LOD}$ & $<$ LOD & 1.48 & 1.41 & $<\mathrm{LOD}$ \\
\hline trans-Pseudoionone & 0.72 & $<\mathrm{LOD}$ & $<$ LOD & $<$ LOD & $<\mathrm{LOD}$ & $<$ LOD & $<$ LOD & $<$ LOD & $<\mathrm{LOD}$ & $<$ LOD & $<\mathrm{LOD}$ & 0.74 & $<\mathrm{LOD}$ & $<\mathrm{LOD}$ \\
\hline Farnesol $(Z, E)$ & 0.59 & $<\mathrm{LOD}$ & $<\mathrm{LOD}$ & 0.62 & $<\mathrm{LOD}$ & 0.58 & $<\mathrm{LOD}$ & $<$ LOD & 0.73 & 0.7 & $<\mathrm{LOD}$ & 0.68 & 0.71 & 0.85 \\
\hline Farnesol $(E, Z)$ & $<\mathrm{LOD}$ & $<$ LOD & $<$ LOD & $<$ LOD & $<$ LOD & $<$ LOD & $<$ LOD & $<$ LOD & $<$ LOD & $<$ LOD & $<$ LOD & $0.7 ?$ & $<$ LOD & $<$ LOD \\
\hline Farnesol $(E, E)$ & 0.13 & 0.23 & 0.24 & 0.91 & 0.51 & 0.59 & 2.44 & 0.42 & 1.36 & 0.19 & 0.16 & 12.06 & 12.07 & 1.84 \\
\hline
\end{tabular}

${ }^{1}$ See Table S2 in Supplementary Materials section for the wine description. 


\section{Materials and Methods}

\subsection{Chemicals}

Sodium chloride (99.5\%), tartaric acid (99.5\%), ethanol CHROMASOLV®(99.8\%), dichloromethane (DCM) (99.8\%), methanol (99.9\%), sodium sulfate (99\%), limonene (97\%), 6-methyl-5-hepten-2-one (99\%), fenchone (98\%), linalool oxide (mixture of cis and trans furanoid isomers), linalool (97\%), $\alpha$-terpineol (98.5\%), nerol (97\%), geraniol (98\%), $\beta$-damascone (90\%), $\beta$-damascenone (98\%), $\alpha$-ionone (90\%), $\beta$-ionone (96\%), pseudoionone (mixture of cis and trans isomers, 97\%), farnesol (mixture of isomers, 95\%), 3-octanol (99\%) and 2,6-dimethyl-6-hepten-2-ol (96\%) were purchased from Sigma-Aldrich (St. Louis, MO, USA). Linalyl acetate (95\%) and $\beta$-citronellol (mixture of enantiomers, 99\%) were purchased from Fluka Chemika (Buchs, Switzerland).

HF-Bond Elut LRC $\mathrm{C}_{18}-\mathrm{OH}$ SPE cartridges $(500 \mathrm{mg}$ ) were purchased from Agilent technologies (Santa Clara, CA, USA) and the 50/30 $\mu \mathrm{m}$ DVB/CAR/PDMS stableflex SPME fiber assembly (23 Ga) was purchased from Supelcoß(Bellefonte, PA, USA). UPLC water was obtained from a Milli-Q filtration system (Millipore Filter Cor., Bedford, MA, USA). Model wine contained 12\% (v/v) ethanol and $5 \mathrm{~g} / \mathrm{L}$ tartaric acid, to which the $\mathrm{pH}$ was adjusted to 3.5 with sodium hydroxide (Sigma-Aldrich, St. Louis, MO, USA). Helium 5.0 was purchased from Afrox (Cape Town, South Africa).

\subsection{Method of cis/trans Ratio Determination in Standard Mixtures}

The standards for linalool oxide (furanoid, cis and trans), pseudoionone (cis and trans) and farnesol $(E, Z ; Z, E ;$ and $E, E)$ contains a mixture of isomers. The standards were diluted to a concentration of $10,000 \mathrm{mg} / \mathrm{L}$ in deuterated chloroform. The ratio of cis:trans was identified using ${ }^{1} \mathrm{H}$ nuclear magnetic resonance (NMR) spectroscopy. NMR spectra were recorded on a Varian unity Inova $300\left({ }^{1} \mathrm{H}\right.$; 300.08 MHz) NMR spectrometer equipped with the sample injector at $30^{\circ} \mathrm{C}$.

Diastereomers containing the cis/trans double bond may be susceptible to interconversion under thermal treatment [20]. Terpenes in particular may be susceptible to this transformation, as demonstrated by multiple sources of literature [20,57-59]. Hence, to confirm the thermal stability of the cis/trans diastereomers at elevated temperatures (as the samples are introduced into the GC inlet at $250{ }^{\circ} \mathrm{C}$ ), the ratio was also determined by GC-FID. The samples diluted to a concentration of $20 \mathrm{mg} / \mathrm{L}$ with dichloromethane and analysed by GC-FID. The ratio obtained from ${ }^{1} \mathrm{H}$ NMR was compared to the ratio of cis and trans diastereomers identified by GC-FID. Importantly, no cis:trans inter-conversion was observed. The cis:trans ratio of linalool oxide (furanoid) and pseudoionone were 57:43 and 29:71 respectively.

\subsection{Method for Dearomatized Wines}

White (Sauvignon Blanc) and red (Cabernet Sauvignon) wines were dearomatized by the following protocol: $500 \mathrm{~mL}$ of wine was reduced by rotary evaporation ( $58 \mathrm{mbar}$, water bath temperature $40^{\circ} \mathrm{C}$ ) for $30 \mathrm{~min}$ to yield a final volume of $400 \mathrm{~mL}$. To this, $60 \mathrm{~mL}$ of absolute ethanol was added and the solution was made up to $500 \mathrm{~mL}$ with water $(12 \%$ ethanol $(v / v))$.

\subsection{Sample Preparation}

\subsubsection{Offline SPE}

The sample preparation was based on work by Piñeiro et al., with some modifications [19]. In summary, the SPE cartridge was conditioned with $4 \mathrm{~mL}$ dichloromethane and $4 \mathrm{~mL}$ methanol, followed by $4 \mathrm{~mL}$ model wine. To the $50 \mathrm{~mL}$ wine sample, $25 \mu \mathrm{L}$ of $400 \mathrm{mg} / \mathrm{L}$ internal standard solution (3-octanol and 2,6-dimethyl-6-hepten-2-ol) was added. The wine sample was loaded onto the cartridge, washed with $6 \mathrm{~mL}$ of water which was followed by drying under vacuum $(-60 \mathrm{KPa})$ for $25 \mathrm{~min}$. The sample was eluted with $2 \mathrm{~mL}$ of DCM, dried over anhydrous sodium sulfate before analysis by GC-MS. 


\subsubsection{Online HS-SPME}

The sample preparation and choice of fiber was based on literature, with some modifications $[2,28,60]$. In summary, to a $20 \mathrm{~mL}$ headspace vial, $2 \mathrm{~g}$ of $\mathrm{NaCl}$ was added. To this, $10 \mathrm{~mL}$ of wine was added, followed by the addition of $50 \mu \mathrm{L}$ of the internal standard solution $(100 \mathrm{mg} / \mathrm{L}$ 3-octanol and 2,6-dimethyl-6-hepten-2-ol in model wine). The samples were hermetically sealed followed by vortexing until the $\mathrm{NaCl}$ was dissolved before the online HS-SPME. The DVB/PDMS/CAR fiber (23 Ga.) was conditioned according to the manufacturer's instructions before analysis. The sample was incubated for $5 \mathrm{~min}$ at $40^{\circ} \mathrm{C}$, followed by sample extraction with agitation ( $250 \mathrm{rpm} ; 3 \mathrm{~s}$ on time, $2 \mathrm{~s}$ off time) at $40^{\circ} \mathrm{C}$ for $25 \mathrm{~min}$, after which the sample was injected for GC-MS analysis.

\subsection{GC-MS Instrumental Parameters}

GC-MS analysis was performed with a 7890B GC (Agilent, Palo Alto, CA, USA), equipped with a 5977B single quadrupole mass detector (Agilent, Palo Alto, CA, USA) and a PAL RSI 85 autosampler (CTC Analytics AG, Zwingen, Switzerland). Chromatographic separation was performed on a Zebron ZB-FFAP capillary column $(60 \mathrm{~m} \times 0.32 \mathrm{~mm} \times 0.5 \mu \mathrm{m}$, Phenomenex, Torrence, CA, USA). The instrumental method was based on work by Marques and Jelen with the following changes [2,28]. The initial oven temperature was $40^{\circ} \mathrm{C}$ held for $5 \mathrm{~min}$, then ramped up to $120^{\circ} \mathrm{C}$ at $8{ }^{\circ} \mathrm{C} / \mathrm{min}$, held for $4 \mathrm{~min}$, then ramped to $170^{\circ} \mathrm{C}$ at $5{ }^{\circ} \mathrm{C} / \mathrm{min}$ and held for 4 minutes, followed by the final temperature ramp to $240^{\circ} \mathrm{C}$ at $5^{\circ} \mathrm{C} / \mathrm{min}$ and held for $3 \mathrm{~min}$. A post run at $240^{\circ} \mathrm{C}$ at $4 \mathrm{~mL} / \mathrm{min}$ for $5 \mathrm{~min}$ was included to thermally clean the column. Sample injection was done in the GC inlet port with the temperature maintained at $250{ }^{\circ} \mathrm{C}$, conducted in splitless mode with the split flow set to $50 \mathrm{~mL} / \mathrm{min}$ for $0.6 \mathrm{~min}$. Gas saver was activated at $2 \mathrm{~min}$ at a flow rate of $20 \mathrm{~mL} / \mathrm{min}$. Helium was used as the carrier gas and the flow rate was set to $1.2 \mathrm{~mL} / \mathrm{min}$ (constant flow). For liquid injections, a $1 \mu \mathrm{L}$ volume in splitless mode was used; for HS-SPME injections, splitless mode was used with sample desorption time set at $10 \mathrm{~min}$. The MS transfer line temperature was maintained at $250^{\circ} \mathrm{C}$.

Data was acquired in the single-ion monitoring (SIM) mode, with the solvent delay set at 12.5 minutes. MS source and quad temperatures were maintained at 230 and $150{ }^{\circ} \mathrm{C}$, respectively, with the ionizing voltage set at $70 \mathrm{eV}$. For the instrumental method development stages, the analyses were performed in scan mode from 50 to $250 \mathrm{amu}$. The retention indices and spectra were compared to NIST11 spectral library. Details of the retention times and indices, quantifier and qualifier ions are listed in Table S3. Data analysis was performed with MassHunter qualitative (B.07.00) and quantitative (B.07.01) workstation software.

\subsection{Method Performance Parameters}

The performance of the sample preparation methods evaluated the qualitative (selectivity) and quantitative (linearity, limits of detection (LOD), limits of quantitation (LOQ), precision and accuracy) parameters.

\subsubsection{Selectivity}

The selectivity was evaluated by spiking model wine and dearomatized white or red wine with the terpenoid stock solution to yield a final concentration of 2 and $20 \mu \mathrm{g} / \mathrm{L}$ for HS-SPME; 20 and $100 \mu \mathrm{g} / \mathrm{L}$ for SPE. The respective sample preparation and analysis was subsequently performed. The resultant chromatograms were compared, and the selectivity was evaluated by qualitatively comparing the results in the presence and absence of interferences from both red and white wine matrices.

\subsubsection{Linearity}

The linearity range was evaluated between 0.28 and $100 \mu \mathrm{g} / \mathrm{L}$ at seven concentrations in model, white and red wine for HS-SPME and 0.88 and $500 \mu \mathrm{g} / \mathrm{L}$ for SPE. The concentration range for the respective analytes are displayed in Table 2. Notably, for red and white wines, a blank deduction was 
performed to allow for comparison with model wine. The linearity correlation coefficients $\left(R^{2}\right)$ were calculated from regression analysis.

\subsubsection{Limits of Detection and Limits of Quantitation}

The LOD and LOQ were calculated as the lowest concentration of the analyte in a sample the resulted in a signal to noise ratio of 3 (LOD) and 10 (LOQ), respectively. The baseline noise was calculated by Agilent's MassHunter software, the autoRMS algorithm was used to calculate the noise within the defined SIM time group for the selected quantitation ion (Table S3). For SPE extractions, the LOD and LOQ are reported in the original $50 \mathrm{~mL}$ sample.

\subsubsection{Accuracy (Recovery Test)}

Accuracy was measured for two levels of the spiked concentration, namely 2 and $20 \mu \mathrm{g} / \mathrm{L}$ for HS-SPME and 20 and $100 \mu \mathrm{g} / \mathrm{L}$ for SPE-the results for which are displayed in Table S4 (Supplementary). Spiked model, red and white wines were extracted in triplicate.

\subsubsection{Precision (Repeatability Test)}

Precision was determined by means as repeatability for the entire procedure, from sample preparation to instrument analysis. The repeatability (\% relative standard deviation for each matrix) was measured in triplicate at 2 and $20 \mu \mathrm{g} / \mathrm{L}$ for HS-SPME and at 20 and $100 \mu \mathrm{g} / \mathrm{L}$ for SPE, and the results hereof are displayed in Table S5 (Supplementary). The RSD values were calculated for the response factors and retention times.

\section{Conclusions}

The measurement of terpenoids was accomplished using both an offline SPE-GC-MS and online HS-SPME-GC-MS method. The sample preparation methods were applied to red, white and model wine, with good separation linearity, precision (repeatability) and accuracy (recovery). Notably, the online HS-SPME-GC-MS method proved to be more sensitive, faster and solvent-free, which is in line with green chemistry principles. To the best of our knowledge, the first cis and trans quantitation for pseudoionone was reported with concentrations ranging from nd to $1.2 \mu \mathrm{g} / \mathrm{L}$ using the HS-SPME method. The internal standards 3-octanol and 2,6-dimethyl-6-hepten-2-ol were compared, and both resulted in acceptable performance levels. Both sample preparation methods evaluated the terpenoid concentrations in white wines and the sum of the compounds ranged 13 to $232 \mu \mathrm{g} / \mathrm{L}$ for the offline SPE-GC-MS sample preparation method and from 15 to $192 \mu \mathrm{g} / \mathrm{L}$ for the online HS-SPME-GC-MS sample preparation method.

Supplementary Materials: The following are available online at http://www.mdpi.com/1420-3049/25/3/657/s1, Figure S1a) SPE GC-MS chromatogram in spiked model wine $(20 \mu \mathrm{g} / \mathrm{L})$, spiked dearomatised white $(20 \mu \mathrm{g} / \mathrm{L})$ and a real white wine sample (ARV16S/B) respectively. Figure S1b) HS-SPME GC-MS chromatogram in spiked model wine $(20 \mu \mathrm{g} / \mathrm{L})$, spiked dearomatised white $(20 \mu \mathrm{g} / \mathrm{L})$ and a real white wine sample (ARV16S/B) respectively. Table S1. Precision and accuracy results for the comparison of 3-octanol and 2,6-dimethyl-6-hepten-2-ol as internal standards. Table S2. Description and alcohol concentration of selected white wines used in this study. Table S3. Calculated and literature retention indices for the analyses of terpenoids using both HS-SPME and SPE. Table S4. Accuracy results by means of recovery (\%) for terpenoids quantitation at $100 \mu \mathrm{g} / \mathrm{L}$ for SPE and $2 \mu \mathrm{g} / \mathrm{L}$ for SPME for model (MW), white (WW) and red (RW) wine respectively. Table S5. Precision results by means of repeatability (\%) for terpenoids quantitation at $100 \mu \mathrm{g} / \mathrm{L}$ for SPE and $2 \mu \mathrm{g} / \mathrm{L}$ for SPME for model (MW), white (WW) and red (RW) wine respectively.

Author Contributions: Conceptualization, A.B.; methodology, A.B and C.W; validation, C.W.; formal analysis, C.W.; investigation, A.B. and C.W.; resources, A.B.; data curation, C.W.; writing-original draft preparation, C.W.; writing - review and editing, A.B.; visualization, C.W.; supervision, A.B.; project administration, A.B.; funding acquisition, A.B. All authors have read and agreed to the published version of the manuscript.

Funding: This research received no external funding. 
Acknowledgments: We would like to acknowledge Lucky Mokwena and Anja du Toit for useful discussion and support in solving practical issues. We would also like to acknowledge Gonzalo Garrido-Bañuelos and Mihaela Mihnea for supplying the white wine samples.

Conflicts of Interest: The authors declare no conflict of interest.

\section{References}

1. Mateo, J.J.; Jiménez, M. Monoterpenes in grape juice and wines. J. Chromatogr. A 2000, 881, 557-567. [CrossRef]

2. Dziadas, M.; Jeleń, H.H. Analysis of terpenes in white wines using SPE-SPME-GC/MS approach. Anal. Chim. Acta 2010, 677, 43-49. [CrossRef] [PubMed]

3. Louw, L.; Tredoux, A.G.J.; van Rensburg, P.; Kidd, M.; Naes, T.; Nieuwoudt, H.H. Fermentation-derived aroma compounds in varietal young wines from South Africa. S. Afr. J. Enol. Vitic. 2010, 31, 213-225. [CrossRef]

4. Cocito, C.; Delfini, C. Simultaneous determination by GC of free and combined fatty acids and sterols in grape musts and yeasts as silanized compounds. Food Chem. 1994, 50, 297-305. [CrossRef]

5. Shinohara, T. Agricultural and Biological Chemistry Gas Chromatographic Analysis of Volatile Fatty Acids in Wines Gas Chromatographic Analysis of Volatile Fatty Acids in Wines. Agric. Biol. Chem. 1985, 497, 5-7.

6. Oliveira, J.M.; Faria, M.; Sá, F.; Barros, F.; Araújo, I.M. C 6 -alcohols as varietal markers for assessment of wine origin. Anal. Chim. Acta 2006, 563, 300-309. [CrossRef]

7. Ryan, D.; Watkins, P.; Smith, J.; Allen, M.; Marriott, P. Analysis of methoxypyrazines in wine using headspace solid phase microextraction with isotope dilution and comprehensive two-dimensional gas chromatography. J. Sep. Sci. 2005, 28, 1075-1082. [CrossRef]

8. Mafata, M.; Stander, M.; Thomachot, B.; Buica, A. Measuring Thiols in Single Cultivar South African Red Wines Using 4,4-Dithiodipyridine (DTDP) Derivatization and Ultraperformance Convergence Chromatography-Tandem Mass Spectrometry. Foods 2018, 7, 138. [CrossRef]

9. De Vries, C.J.; Mokwena, L.M.; Buica, A.; McKay, M. Determination of Volatile Phenol in Cabernet Sauvignon Wines, Made from Smoke-affected Grapes, by using HS-SPME GC-MS. S. Afr. J. Enol. Vitic. 2016, 37, $15-21$. [CrossRef]

10. Araujo, L.D.; Vannevel, S.; Buica, A.; Callerot, S.; Fedrizzi, B.; Kilmartin, P.A.; du Toit, W.J. Indications of the prominent role of elemental sulfur in the formation of the varietal thiol 3-mercaptohexanol in Sauvignon blanc wine. Food Res. Int. 2017, 98, 79-86. [CrossRef]

11. Díaz-Maroto, M.C.; Sánchez-Palomo, E.; Pérez-Coello, M.S. Fast screening method for volatile compounds of oak wood used for aging wines by headspace SPME-GC-MS (SIM). J. Agric. Food Chem. 2004, 52, 6857-6861. [CrossRef] [PubMed]

12. Marchand, S.; De Revel, G.; Bertrand, A. Approaches to wine aroma: Release of aroma compounds from reactions between cysteine and carbonyl compounds in wine. J. Agric. Food Chem. 2000, 48, 4890-4895. [CrossRef] [PubMed]

13. Wang, J.; Capone, D.L.; Wilkinson, K.L.; Jeffery, D.W. Chemical and sensory profiles of rosé wines from Australia. Food Chem. 2016, 196, 682-693. [CrossRef] [PubMed]

14. Wu, Y.; Duan, S.; Zhao, L.; Gao, Z.; Luo, M.; Song, S.; Xu, W.; Zhang, C.; Ma, C.; Wang, S. Aroma characterization based on aromatic series analysis in table grapes. Sci. Rep. 2016, 6, 1-16. [CrossRef]

15. Black, C.A.; Parker, M.; Siebert, T.E.; Capone, D.L.; Francis, I.L. Terpenoids and their role in wine flavour: Recent advances. Aust. J. Grape Wine Res. 2015, 21, 582-600. [CrossRef]

16. Wood, C.; Siebert, T.E.; Parker, M.; Capone, D.L.; Elsey, G.M.; Pollnitz, A.P.; Eggers, M.; Meier, M.; Vössing, T.; Widder, S.; et al. From wine to pepper: Rotundone, an obscure sesquiterpene, is a potent spicy aroma compound. J. Agric. Food Chem. 2008, 56, 3738-3744. [CrossRef]

17. Câmara, J.S.; Herbert, P.; Marques, J.C.; Alves, M.A. Varietal flavour compounds of four grape varieties producing Madeira wines. Anal. Chim. Acta 2004, 513, 203-207. [CrossRef]

18. Serra, S. Recent advances in the synthesis of carotenoid-derived flavours and fragrances. Molecules 2015, 20, 12817-12840. [CrossRef]

19. Piñeiro, Z.; Palma, M.; Barroso, C.G. Determination of terpenoids in wines by solid phase extraction and gas chromatography. Anal. Chim. Acta 2004, 513, 209-214. [CrossRef] 
20. Cataldo, F. Thermal depolymerization and pyrolysis of cis-1,4-polyisoprene: Preparation of liquid polyisoprene and terpene resin. J. Anal. Appl. Pyrolysis 1998, 44, 121-130. [CrossRef]

21. Skinkis, P.A.; Bordelon, B.P.; Butz, E.M. Effects of sunlight exposure on berry and wine monoterpenes and sensory characteristics of traminette. Am. J. Enol. Vitic. 2010, 61, 147-156.

22. Fariña, L.; Boido, E.; Carrau, F.; Versini, G.; Dellacassa, E. Terpene compounds as possible precursors of 1,8-cineole in red grapes and wines. J. Agric. Food Chem. 2005, 53, 1633-1636. [CrossRef] [PubMed]

23. Ebeler, S.E. Analytical chemistry: Unlocking the secrets of wine flavor. Food Rev. Int. 2001, 17, 45-64. [CrossRef]

24. Polášková, P.; Herszage, J.; Ebeler, S.E. Wine flavor: Chemistry in a glass. Chem. Soc. Rev. 2008, 37, 2478-2489. [CrossRef]

25. De Villiers, A.; Alberts, P.; Tredoux, A.G.J.; Nieuwoudt, H.H. Analytical techniques for wine analysis: An African perspective; a review. Anal. Chim. Acta 2012, 730, 2-23. [CrossRef]

26. Williams, P.J.; Strauss, C.R.; Wilson, B. Classification of the Monoterpenoid Composition of Muscat Grapes. Am. J. Enol. Vitic. 1981, 32, 230-235.

27. Kishimoto, T.; Wanikawa, A.; Kagami, N.; Kawatsura, K. Analysis of hop-derived terpenoids in beer and evaluation of their behavior using the stir bar-sorptive extraction method with GC-MS. J. Agric. Food Chem. 2005, 53, 4701-4707. [CrossRef]

28. Câmara, J.S.; Arminda Alves, M.; Marques, J.C. Development of headspace solid-phase microextraction-gas chromatography-mass spectrometry methodology for analysis of terpenoids in Madeira wines. Anal. Chim. Acta 2006, 555, 191-200. [CrossRef]

29. Andujar-Ortiz, I.; Moreno-Arribas, M.V.; Martín-Álvarez, P.J.; Pozo-Bayón, M.A. Analytical performance of three commonly used extraction methods for the gas chromatography-mass spectrometry analysis of wine volatile compounds. J. Chromatogr. A 2009, 1216, 7351-7357. [CrossRef]

30. Gamero, A.; Wesselink, W.; de Jong, C. Comparison of the sensitivity of different aroma extraction techniques in combination with gas chromatography-mass spectrometry to detect minor aroma compounds in wine. J. Chromatogr. A 2013, 1272, 1-7. [CrossRef]

31. Tufariello, M.; Pati, S.; D'Amico, L.; Bleve, G.; Losito, I.; Grieco, F. Quantitative issues related to the headspace-SPME-GC/MS analysis of volatile compounds in wines: The case of Maresco sparkling wine. LWT 2019, 108, 268-276. [CrossRef]

32. Merkle, S.; Kleeberg, K.; Fritsche, J. Recent Developments and Applications of Solid Phase Microextraction (SPME) in Food and Environmental Analysis-A Review. Chromatography 2015, 2, 293-381. [CrossRef]

33. Lanaridis, P.; Salaha, M.J.; Tzourou, I.; Tsoutsouras, E.; Karagiannis, S. Volatile compounds in grapes and wines from two Muscat varieties cultivated in Greek Islands. J. Int. Sci. Vigne Vin. 2002, 36, 39-47. [CrossRef]

34. Bavčar, D.; Česnik, H.B. Validation of the method for the determination of some wine volatile compounds. Acta Agric. Slov. 2011, 97, 285-293. [CrossRef]

35. Vilanova, M.; Genisheva, Z.; Graña, M.; Oliveira, J.M. Determination of odorants in varietal wines from international grape cultivars (Vitis vinifera) grown in NW Spain. S. Afr. J. Enol. Vitic. 2013, 34, 212-222. [CrossRef]

36. Michlmayr, H.; Nauer, S.; Brandes, W.; Schümann, C.; Kulbe, K.D.; Del Hierro, A.M.; Eder, R. Release of wine monoterpenes from natural precursors by glycosidases from Oenococcus oeni. Food Chem. 2012, 135, 80-87. [CrossRef]

37. Park, S.K.; Morrison, J.C.; Adams, D.O.; Noble, A.C. Distribution of Free and Glycosidically Bound Monoterpenes in the Skin and Mesocarp of Muscat of Alexandria Grapes during Development. J. Agric. Food Chem. 1991, 39, 514-518. [CrossRef]

38. Baron, M.; Prusova, B.; Tomaskova, L.; Kumsta, M.; Sochor, J. Terpene content of wine from the aromatic grape variety "Irsai Oliver" (Vitis vinifera L.) depends on maceration time. Open Life Sci. 2017, 12, 42-50. [CrossRef]

39. Zalacain, A.; Marín, J.; Alonso, G.L.; Salinas, M.R. Analysis of wine primary aroma compounds by stir bar sorptive extraction. Talanta 2007, 71, 1610-1615. [CrossRef]

40. Buttery, R.G.; Teranishi, R.; Ling, L.C.; Turnbaugh, J.G. Quantitative and Sensory Studies on Tomato Paste Volatiles. J. Agric. Food Chem. 1990, 38, 336-340. [CrossRef] 
41. Wang, Y.; Zhang, C.; Li, J.; Xu, Y. Different influences of $\beta$-glucosidases on volatile compounds and anthocyanins of Cabernet Gernischt and possible reason. Food Chem. 2013, 140, 245-254. [CrossRef] [PubMed]

42. Callejón, R.M.; Ubeda, C.; Ríos-Reina, R.; Morales, M.L.; Troncoso, A.M. Recent developments in the analysis of musty odour compounds in water and wine: A review. J. Chromatogr. A 2016, 1428, 72-85. [CrossRef] [PubMed]

43. Sadoughi, N.; Schmidtke, L.M.; Antalick, G.; Blackman, J.W.; Steel, C.C. Gas chromatography-mass spectrometry method optimized using response surface modeling for the quantitation of fungal off-flavors in grapes and wine. J. Agric. Food Chem. 2015, 63, 2877-2885. [CrossRef] [PubMed]

44. Kaack, K.; Christensen, L.P.; Hughes, M.; Eder, R. Relationship between sensory quality and volatile compounds of elderflower (Sambucus nigra L.) extracts. Eur. Food Res. Technol. 2006, 223, 57-70. [CrossRef]

45. Pino, J.A.; Queris, O. Analysis of volatile compounds of mango wine. Food Chem. 2011, 125, 1141-1146. [CrossRef]

46. Ferreira, V.; López, R.; Cacho, J.F. Quantitative determination of the odorants of young red wines from different grape varieties. J. Sci. Food Agric. 2000, 80, 1659-1667. [CrossRef]

47. Selli, S.; Canbas, A.; Varlet, V.; Kelebek, H.; Prost, C.; Serot, T. Characterization of the most odor-active volatiles of orange wine made from a Turkish cv. Kozan (Citrus sinensis L. Osbeck). J. Agric. Food Chem. 2008, 56, 227-234. [CrossRef]

48. Elsharif, S.A.; Banerjee, A.; Buettner, A. Structure-odor relationships of linalool, linalyl acetate and their corresponding oxygenated derivatives. Front. Chem. 2015, 3, 1-10. [CrossRef]

49. Mahattanatawee, K.; Rouseff, R.; Valim, M.F.; Naim, M. Identification and aroma impact of norisoprenoids in orange juice. J. Agric. Food Chem. 2005, 53, 393-397. [CrossRef]

50. Guth, H. Quantitation and Sensory Studies of Character Impact Odorants of Different White Wine Varieties. J. Agric. Food Chem. 1997, 45, 3027-3032. [CrossRef]

51. Hirvi, T.; Honkanen, E. The aroma of blueberries. J. Sci. Food Agric. 1983, 34, 992-996. [CrossRef]

52. King, A.J.; Dickinson, J.R. Biotransformation of hop aroma terpenoids by ale and lager yeasts. FEMS Yeast Res. 2003, 3, 53-62. [CrossRef] [PubMed]

53. Zea, L.; Moyano, L.; Moreno, J.; Cortes, B.; Medina, M. Discrimination of the aroma fraction of Sherry wines obtained by oxidative and biological ageing. Food Chem. 2001, 75, 79-84. [CrossRef]

54. Beckner Whitener, M.E.; Stanstrup, J.; Panzeri, V.; Carlin, S.; Divol, B.; Du Toit, M.; Vrhovsek, U. Untangling the wine metabolome by combining untargeted SPME-GCxGC-TOF-MS and sensory analysis to profile Sauvignon blanc co-fermented with seven different yeasts. Metabolomics 2016, 12, 1-25. [CrossRef]

55. Vilanova, M.; Sieiro, C. Determination of free and bound terpene compounds in Albariño wine. J. Food Compos. Anal. 2006, 19, 694-697. [CrossRef]

56. Song, M.; Fuentes, C.; Loos, A.; Tomasino, E. Free monoterpene isomer profiles of Vitis vinifera L. Cv. white wines. Foods 2018, 7, 27. [CrossRef]

57. Capone, D.L.; Van Leeuwen, K.; Taylor, D.K.; Jeffery, D.W.; Pardon, K.H.; Elsey, G.M.; Sefton, M.A. Evolution and occurrence of 1,8-cineole (Eucalyptol) in Australian wine. J. Agric. Food Chem. 2011, 59, 953-959. [CrossRef]

58. Pedersen, D.S.; Capone, D.L.; Skouroumounis, G.K.; Pollnitz, A.P.; Sefton, M.A. Quantitative analysis of geraniol, nerol, linalool, and $\alpha$-terpineol in wine. Anal. Bioanal. Chem. 2003, 375, 517-522. [CrossRef]

59. Williams, C.; Ferreira, M.; Monflier, E.; Mapolie, S.F.; Smith, G.S. Synthesis and hydroformylation evaluation of Fréchet-type organometallic dendrons with N,O-salicylaldimine Rh(i) complexes at the focal point. Dalt. Trans. 2018, 47. [CrossRef]

60. Prosen, H.; Janeš, L.; Strlič, M.; Rusjan, D.; Kočar, D. Analysis of free and bound aroma compounds in grape berries using headspace solid-phase microextraction with GC-MS and a preliminary study of solid-phase extraction with LC-MS. Acta Chim. Slov. 2007, 54, 25-32.

Sample Availability: Samples of the compounds are not available from the authors.

(C) 2020 by the authors. Licensee MDPI, Basel, Switzerland. This article is an open access article distributed under the terms and conditions of the Creative Commons Attribution (CC BY) license (http://creativecommons.org/licenses/by/4.0/). 